\title{
International and National Legal Framework for Maritime Environment Protection in the Hellenic Legal Order
}

\author{
Korontzis Tryfon ${ }^{1}$ \\ ${ }^{1}$ Hellenic National Faculty of Local Government (ESTA), Piraeus, Hellas \\ Correspondence: Korontzis Tryfon, Hellenic National Faculty of Local Government (ESTA), 228 Petrou Ralli \\ Street, Nikaia, Piraeus, PC 18454, Hellas. Tel: 30-693-651-8728. E-mail: tmkoront@otenet.gr
}

Received: August 7, 2012 Accepted: August 22, 2012 Online Published: October 26, 2012

doi:10.5539/ilr.v1n1p73 URL: http://dx.doi.org/10.5539/ilr.v1n1p73

\begin{abstract}
It is known that the subjects of maritime pollution, because of its international extensions and extensive environmental damage that this consequences, are regulated by International Conventions and basically by the International Convention MARPOL 1973, which was ratified (with its protocol of 1978) by the law 1269/1982.

However, these regulations were judged in European Union level as insufficient. Thus began from the European Union an effort for creation of a European regulating frame, equipped with effective, deterrent and proportional sanctions, basically penal, for the successful confrontation of pollution problems created by vessels.

In parallel with the international and European legislative frame has been developed also national legal frame in which are forecasted not only penal sanctions but also administrative and ddisciplinary which are imposed in the Hellenic seamen depending the case. All these legal forecasts aim in the protection of sea environment one of the most important for people's existence.
\end{abstract}

Keywords: maritime environment, international-national legislation, penal-administrative-disciplinary sanctions, prohibition of vessels departure, Hellenic Coast Guard (HCG)

\section{Introduction}

Environmental pollution due to the technological high progress and the continuously industrial development has assumed dangerous and in many cases, catastrophic dimensions especially for the maritime environment. Pollution of teas is a problem that affects/is affected by many factors and as such phenomenon has global dimension. Global dimension is difficult to be combated not only because of its extension that might have, but mainly because of its liquidity.

The effects of pollution incidents can cause damage in a local or wider level to ecosystems, to economic activities and actions that sometimes cannot be traced to a real economic cost, such as the recreation of the people and the pleasure offered by engaging with it.

Especially maritime pollution has particularly adverse economic consequences in regions where societies or State depend from fishing and/or tourism.

The preservation of the natural environment from pollution and destruction is an intense and crucial economic and sociopolitical problem and employ people and means in order to be prevented the destruction of the natural environment and human living conditions.

In this concise study will be developed the most important legal provisions (International and National) constituting the legal framework which defines the protection of the maritime environment in Hellas, while in each case will be developed and the remedies which can be submitted by anyone who has a legitimate interest. Also it will be developed the concept of vessels prohibition departure, a legal institution which is predicted by the Hellenic legal order, measure which contributes not only to the restoration of the law order but also in the safeguarding of individuals and public interests case by case. Finally, the study will close with the formulation of conclusions. 


\section{Maritime Environment Protection}

\subsection{Content of Maritime Environment and Pollution Concept}

"Environment" is meant the total of natural and anthropogenic factors and elements that are in interaction and affect the ecological balance, quality of life, health of people, historical and cultural tradition and the aesthetic values.

"Pollution" is meant the presence at sea of any substance that alters the natural condition of the seawater or makes it harmful to human health or to the fauna and flora of sea beds and generally unsuitable for its intended uses (Note 1).

\subsection{Violation of National Legislation}

Environmental protection is a constitutional requirement (article 24 of Hellenic Constitution) and therefore a State obligation, but also right of any citizen (Note 2).

The Hellenic Coast Guard (HCG) (Note 3) is the main body (Law Enforcement Agency-LEA) responsible for the prevention of seas pollution as also for the protection of Hellenic coastlines, pollutions which can endanger people's interests or of the wider society or to degrade the maritime environment.

In order to combat this problem (Note 4), which in the last years occupies very intensively the whole humanity, and in order to take the necessary preventive measures, in HCG Headquarter has been established a specialized service unit under the name Division of Maritime Environment Protection (DMEP-DPTHP)(Note 5).

The international experience and practice reveals that whatever measures are taken, pollution incidents cannot be eliminated completely, since the time, place and circumstances of an incident cannot be envisaged, while most incidents due to imponderables.

For these reasons, emergency planning consists today in international level the best tool and weapon of the competent authorities, in determining the required level of intervention, depending on the severity of each incident (Note 6).

The most important legislative act concerning the protection of the maritime environment is the Presidential Decree (PD) 55/1998 (A'58), with which have been consolidated into a single text all the provisions of law 743/1977 (A' 319). In this PD in which are incorporated and the most important international provisions, are also contained the penal, disciplinary and administrative penalties for offenders who violate its provisions.

This law is being enforced and after the entry into force of law 1650/1986 ( $\mathrm{A}^{\prime} 160$ ), as is defined in its article 32 paragraph 1 (Note 7).

Against the decision imposing a fine for violation of PD 55/1998 provisions and after the publication of law 2690/1999 ( $\mathrm{A}^{\prime}$ 45) as was modified by the law 3659/2008 (A' 77) and law 2717/1999 (A' 97), is allowed initially the submission of remedy or hierarchical appeal to the administrative authority that issued the offended action and the hierarchical to the superior of this. Then follows after the preceding procedure the submission of appeal to the competent Administrative Court (for an amount to 586.94 E to the One Member Administrative Court and up of this amount to the Three Members Administrative Court) within sixty (60) days. The submission of appeal does not suspend the execution and attestation of fine (Note 8).

The fines which are imposed according to articles 13 and 14 of 743/77 (A' 319)(Note 9) becomes in Special Fund of Regulatory and City Planning Implementation (ETERPS) (Note 10). 2.3 Violation of Provisions and Regulations of the International Convention "for the Prevention of Sea Pollution
by Ships" Marpol 73/78

The above mentioned provision was ratified by the law 1269/1982 (A'89).According to article 5 of this law, its provisions as also and the provisions of the regulatory acts which will be issued according to its authorization, are implemented in Hellenic ships, in vessels under foreign flag arriving at Hellenic ports and bays or are in Hellenic territorial waters, at installations located in Hellas in which approach ships in order to perform any kind of work and action and finally in ships, machinery, devices and equipment of any kind that is produced in Hellas and is intended for installations or vessels.

As competent authorities for its enforcement (article 6) are defined the Directorate of Vessels Inspection (KEEP) (Note 11), Port Police Authorities and Consular Port Police Authorities.

By reasoned decision issued by the competent authorities (article 6), according to article 9 of this law, to the offenders of its provisions as well as to the offenders (Note 12)of PD and Ministerial Decisions (MD) (Note 13) which will be issued in implementing of it is imposed fine amount to 14.673, 51E (Note 14). 
It is possible with the notification of the decision imposing fine to be implemented the measure of vessel departure until the fine to be paid or be deposited a guarantee letter of equal amount.

Against the decision imposing fine can be followed the same legal procedure as have been mentioned before. If the decision imposing a fine is issued by Consular Port Police Authority because the infringement certified in the area of its responsibility, or arrived in its area of jurisdiction vessel, the appeal is submitted to the Piraeus Administrative Court since and in this case will be kept the predicted in the law concerning the submission of remedy or of hierarchical appeal to the administrative authority which has issued the offended action or to the superior of this.

The fines which are imposed according to article 9 of the law 1269/1982 (A' 89) and are collected according to the Code of Public Income Collection (COPIC-KEDE) (Note 15) in implementation of article 18, paragraph 1 of PD 55/1998 are income of the Special Fund of Regulatory and City Planning Implementation (ETERPS) (Note 16)

\subsection{Violation of provisions and Regulations of other International Conventions (Note 17) and International Protocols}

Additionally of the above national and international legal texts, which are referred to the protection of the maritime environment from pollution, also are in force and the following legal texts which have been ratified by Hellas and have been incorporated into the national legal order. These are:

a. Law 314/1976 (A' 106),"Ratification of the International Convention on Civil Liability for Oil Pollution Damage 1969 signed in Brussels and regulating of related issues", as has been amended and being in force by the law 1638/1986 (A'108).

Penalties are predicted in article 5, as was amended by the law 2881/2001 (A'16) and the prohibition of vessel departure is lifted by the deposit of guarantee letter of a Bank which functions legally in Hellas and for equal amount of the fine. As concerns the implementation of legal procedures if the decision imposing a fine is issued by Consular Port Police Authority because the infringement certified in the area of its responsibility, or arrived in its area of jurisdiction vessel, the appeal is submitted to the Piraeus Administrative Court since and in this case will be kept the predicted in the law concerning the submission of remedy or of hierarchical appeal to the administrative authority which has issued the offended action or to the superior of this.

b. Law 855/1978 (A' 235),"Ratification of the International Convention Protection of the Mediterranean Sea against Pollution with the attachment to this annex as also and the protocols "Protocol for the Prevention of Pollution of the Mediterranean Sea by Dumping from Ships and aircrafts" and "Concerning Co - operation in Combating Pollution of the oil and Other Harmful Substances in Cases of Emergency", after attachments in these Annexes signed in Barcelona in 1976" as was amended by the law 3022/2002 (A'144)paragraph(A) 3 of the second article and article third of law 3497/2006 (A'219).

As competent authorities for the infringements certification according to article 3 paragraph 3 as far concerns the HCG are the Port Police Authorities.

The prohibition of vessel departure is lifted by the deposit of guarantee letter of a Bank which functions legally in Hellas and for equal amount of the fine. Sailing can be permitted without fine to be paid or without to be deposited guarantee letter from Bank, after approval of the Minister for one or more voyages, if imperative transportation or other reasons justifying sailing, or is impossible according to the circumstances the deposit of guarantee Bank letter and according to the discretion of the Minister is offered another adequate guarantee.

Administrative penalties are predicted in the article 5, paragraph 1. b. I and as far as concerns the implementation of legal procedures if the decision imposing a fine is issued by Consular Port Police Authority because the infringement certified in the area of its responsibility, or arrived in its area of jurisdiction vessel, the appeal is submitted to the Piraeus Administrative Court since and in this case will be kept the predicted in the law concerning the submission of remedy or of hierarchical appeal to the administrative authority which has issued the offended action or to the superior of this.

c. Law 1147/1981 (A' 110),"Ratification of the International Convention of Dumping and Wastes and Other Matter 1973 signed in London, Mexico City, Moscow and Washington" as has been amended and being in force.

The prohibition of vessel departure is lifted by the deposit of guarantee letter of a Bank which functions legally in Hellas and for equal amount of the fine. Sailing can be permitted without fine to be paid or without to be deposited guarantee letter from Bank, after approval of the Minister for one or more voyages, if imperative transportation or other reasons justifying sailing, or is impossible according to the circumstances the deposit of 
guarantee Bank letter and according to the discretion of the Minister is offered another adequate guarantee.

As competent authorities for the infringements certification according to article 3 paragraph1 as far concerns the HCG are the Port Police Authorities.

The administrative penalties are predicted in article 5, paragraph $\mathrm{b}$. and as far as concerns the implementation of legal procedures if the decision imposing a fine is issued by Consular Port Police Authority because the infringement certified in the area of its responsibility, or arrived in its area of jurisdiction vessel, the appeal is submitted to the Piraeus Administrative Court after and in this case will be kept the predicted in the law concerning the submission of remedy or of hierarchical appeal to the administrative authority which has issued the offended action or to the superior of this.

d. Law 1634/1986 (A' 104), Ratification of the protocols 1980 "For the protection of the Mediterranean Sea against pollution from land-based sources" and 1982 "Protocol Concerning Mediterranean Special Protected Areas".

As competent authorities for the infringements certification according to article 3 paragraph 1 as far concerns the HCG are the Port Police Authorities.

The prohibition of vessel departure is lifted by the deposit of guarantee letter of a Bank which functions legally in Hellas and for equal amount of the fine. Sailing can be permitted without fine to be paid or without to be deposited guarantee letter from Bank, after approval of the Minister for one or more voyages, if imperative transportation or other reasons justifying sailing, or is impossible according to the circumstances the deposit of guarantee Bank letter and according to the discretion of the Minister is offered another adequate guarantee.

The administrative penalties are predicted in article 3 and as far as concerns the implementation of legal procedures if the decision imposing a fine is issued by Consular Port Police Authority because the infringement certified in the area of its responsibility, or arrived in its area of jurisdiction vessel, the appeal is submitted to the Piraeus Administrative Court after and in this case will be kept the predicted in the law concerning the submission of remedy or of hierarchical appeal to the administrative authority which has issued the offended action or to the superior of this.

e. Law 1638/1986 (A' 108), Ratification of the International Convention signed in Brussels in 1971 "On the Establishment of an International Fund for Compensation for Oil Pollution Damage" and regulating of related items.

Penalties are predicted in article 5 of the law and as far as concern as concerns the implementation of legal procedures if the decision imposing a fine is issued by Consular Port Police Authority because the infringement certified in the area of its responsibility, or arrived in its area of jurisdiction vessel, the appeal is submitted to the Piraeus Administrative Court after and in this case will be complied the predicted in the law concerning the submission of remedy or of hierarchical appeal to the administrative authority which has issued the offended action or to the superior of this (Note 18).

f. Law 2252/1994 (A' 192), Ratification of the International Convention “On Oil Pollution Preparedness, response and cooperation 1990 and other provisions"(Note 19).

As competent authorities for the infringements certification according to article 2 paragraph B are the Port Police Authorities and the Directorate of Vessels Inspection (KEEP) (Note 20). It must be noted that according to article 5 of this specific law National Coordinator for the implementation of the National Emergency Situation Plan was the National Joint Rescue Coordination Center (JRCC -EKSED) of the HCG which was replaced by the HCG Operational Center (Note 21).

The administrative penalties are predicted in article 9 and as far as concerns the implementation of legal procedures if the decision imposing a fine is issued by Consular Port Police Authority because the infringement certified in the area of its responsibility, or arrived in its area of jurisdiction vessel, the appeal is submitted to the Piraeus Administrative Court since and in this case will be kept the predicted in the law concerning the submission of remedy or of hierarchical appeal to the administrative authority which has issued the offended action or to the superior of this.

It is possible with the notification of the decision imposing a fine to be implemented the measure of vessel departure prohibition until to be paid the fine or to be deposit a guarantee letter of equal amount.

g. Law 3100/2003 (A' 20), "Ratification of the Protocol on preparedness, response and cooperation to pollution incidents by hazardous and noxious substances, 2000".

In article 5 of that law, entitled "Extension of law 2252/1994 provisions implementation", is defined that the 
articles third, fourth, fifth, sixth, seventh, eighth and ninth of law 2252/1994 as being in force, are implemented and for the "Protocol on preparedness, response and cooperation to pollution incidents by hazardous and noxious substances, 2000".

As competent authorities for the infringements certification according to article 4 paragraph 1 are the Port Police Authorities, the Directorate of Vessels Inspection (KEEP) (Note 22) and the Consular Port Police Authorities.

Administrative penalties are predicted in article 9and as far as concerns the implementation of legal procedures if the decision imposing a fine is issued by Consular Port Police Authority because the infringement certified in the area of its responsibility, or arrived in its area of jurisdiction vessel, the appeal is submitted to the Piraeus Administrative Court since and in this case will be kept the predicted in the law concerning the submission of remedy or of hierarchical appeal to the administrative authority which has issued the offended action or to the superior of this.

It is possible with the notification of the decision imposing a fine to be implemented the measure of vessel departure prohibition until to be paid the fine or to be deposit a guarantee letter of equal amount.

h. Law 3393/2005 (A' 243), "Ratification of the International Convention on Civil Liability for Bunker Oil Pollution Damage, 2001".

As competent authorities for the infringements certification according to article according to article 6 are the Port Police Authorities and the Consular Port Police Authorities.

Penalties are predicted in article 6and as far as concerns the implementation of legal procedures if the decision imposing a fine is issued by Consular Port Police Authority because the infringement certified in the area of its responsibility, or arrived in its area of jurisdiction vessel, the appeal is submitted to the Piraeus Administrative Court since and in this case will be kept the predicted in the law concerning the submission of remedy or of hierarchical appeal to the administrative authority which has issued the offended action or to the superior of this.

It is possible with the notification of the decision imposing a fine to be implemented the measure of vessel departure prohibition until to be paid the fine or to be deposit a guarantee letter of equal amount.

i. Law 3394/2005 (A' 243), "Ratification of the International Convention on the Control of Harmful AntiFowling Systems on Ships, 2001".

In article 6, entitled "Penalties - Appeals" paragraph 1, verse (b) is defined: "in the case of infringements by ships is possible with the notification of the decision imposing a fine to be implemented the measure of vessel prohibition departure until to be paid the fine or to be deposit a guarantee Bank letter of equal amount".

As far as concern as concerns the implementation of legal procedures if the decision imposing a fine is issued by Consular Port Police Authority because the infringement certified in the area of its responsibility, or arrived in its area of jurisdiction vessel, the appeal is submitted to the Piraeus Administrative Court since and in this case will be kept the predicted in the law concerning the submission of remedy or of hierarchical appeal to the administrative authority which has issued the offended action or to the superior of this.

j. Law 3482/2006 (A' 163), "Ratification of the Protocol of 2003 to the International Convention on the establishment of an International Fund for Compensation for Oil Pollution Damage, 1992 and other provisions".

Penalties are predicted in article 4, which provides that the fines are imposed by a reasoned decision of the authority in the jurisdiction of which is situated the installation. As far as concerns the implementation of legal procedures if the decision imposing a fine is issued by Consular Port Police Authority because the infringement certified in the area of its responsibility, or arrived in its area of jurisdiction vessel, the appeal is submitted to the Piraeus Administrative Court since and in this case will be kept the predicted in the law concerning the submission of remedy or of hierarchical appeal to the administrative authority which has issued the offended action or to the superior of this.

m. Directive with No 2005/35issued by the European Parliament and the Council on September 07, 2005 titled on ship-source pollution and on the introduction of penalties for infringements (OJ L 255, 30-09-2005) (Note 23).

Violations are predicted in article 4, while in article 8 are defined the sanctions. More specifically is defined that Member -States are taking all the necessary measures in order to ensure that violations of article 4 are punishable by effective, proportionate and dissuasive sanctions in which may include penal or administrative penalties. Also, each Member State takes the necessary measures in order to ensure that the penalties of paragraph 1 are enforced to any responsible culpable of violation according to article 4 . 
As far as concerns the implementation of legal procedures if the decision imposing a fine is issued by Consular Port Police Authority because the infringement certified in the area of its responsibility, or arrived in its area of jurisdiction vessel, the appeal is submitted to the Piraeus Administrative Court since and in this case will be kept the predicted in the law concerning the submission of remedy or of hierarchical appeal to the administrative authority which has issued the offended action or to the superior of this.

The fines which are imposed are collected according to the Code of Public Income Collection (COPIC-KEDE) in implementation of article 18, paragraph 1 of PD 55/1998 are income of the Special Fund of Regulatory and City Planning Implementation (ETERPS) (Note 24).

If the decision imposing a fine is issued by Consular Port Police Authority because the infringement certified in the area of its responsibility, or arrived in its area of jurisdiction vessel, the appeal is submitted to the Piraeus Administrative Court since and in this case will be kept the predicted in the law concerning the submission of remedy or of hierarchical appeal to the administrative authority which has issued the offended action or to the superior of this.

\subsection{For Violation of General Port Regulations}

According to article 156 of the Legislative Decree (LD) 187/73 (A' 163), as has been modified and being in force by the article 10 of law 1940/1991 (A'40), for the enforcement of Administrative Police competences (Note 25) concerning Port Police Authorities, issue provisions with the type of General and Special Port Regulations. More specifically:

(a) General Port Regulations (GPR), regulate common to all Port Police Authorities items, are issued by the Head of HCG, are approved by the Minister of Shipping and Aegean (MSA), are published in the Official Gazette and are implemented in the areas of responsibility of all Port Police Authorities.

(b) Special Port Regulations (SPR), regulate special features of each port items which are not regulated by the GRP, are issued by the Port Police Authorities (Central Port Police Authorities, Port Police Authorities, Sub Port Police Authorities) and after receiving the opinion of the Prefect are approved by the MSA and are published in the Official Gazette.

The most important GRP reported to this study are as follows:

a. Approval by the MD with No 3131.1/01/99 issued by the Minister of Mercantile Marine (MMM) of GPR «18», titled [Preconditions and security measures for loading or unloading or transfusion work. ......], (B' 12).

b. Approval by the MD with No 2122/06/2001 issued by the MMM of GRP«25», titled [replacement and supplement of some provisions ......] (B'219).

c. Approval by the MD with No 5219/Ф 23/01/02 issued by the MMM of GRP«29», titled [Completion of GPR «18»provisions] (B'58).

d. Approval by the MD with No. 2122/30/2003 issued by the MMM of GRP«34», titled [Preconditions and security measures...... ( $\left.\mathrm{B}^{\prime} 700\right)$ and

e. approval by the MD with No 2122/16/05 issued by the MMM of GRP «40», titled [replacement and completion........] (B'1010).

As far as concerns the implementation of legal procedures if the decision imposing a fine is issued by Consular Port Police Authority because the infringement certified in the area of its responsibility, or arrived in its area of jurisdiction vessel, the appeal is submitted to the Piraeus Administrative Court since and in this case will be kept the predicted in the law concerning the submission of remedy or of hierarchical appeal to the administrative authority which has issued the offended action or to the superior of this. Additionally for this specific case implement paragraphs 4 and 5 of the article 156 of the LD 187/1973.

Also relevant with this item is the PD 293/1986 (A' 129), "Implementation of Regulation Rules for the safe bunkering of the ships" which regarding penalties is enforced article 45 of LD187/1973 as has been modified and is in force (Note 26).

\section{Prohibition of Vessels Departure (Note 27)}

\subsection{For Violation of National Legislation Provision for Maritime Environment Protection}

The most important legal piece of legislation as has been mentioned on the protection of the maritime environment is the PD 55/1998 (A'58). In this of legislation in which are incorporated and the most important international provisions are included penal, disciplinary and administrative penalties for offenders of its provisions. 
This law is implemented and after the entry into force of law 1650/1986, as is defined in its article 32 paragraph 1. Administrative sanctions are imposed according to article $13 \mathrm{~B}$. Concertedly the procedures of infringements ascertain and appeal submission against decisions imposing a fine is defined in article 14. Concretely as far as concerns the procedure of administrative penalties imposition, responsible for infringement ascertain and fine imposition is the nearest to the place of the offence Authority or the Authority of the first port of vessel arrival after the violation.

In particular, except article 4 paragraph 2 of law 743/1977, where the Port Police Authority can prohibit the vessel departure in case that according to article 14 of the same law, the ship does not deliver petroleum mixtures and waste to reception facilities, prohibition of vessels departure can also be imposed from the time of the infringement certification (article 14, paragraph 5 of law 743/77) and until fine payment.

The prohibition of vessel departure is lifted by the deposit of guarantee letter of a Bank which functions legally in Hellas and for equal amount of the fine. Sailing can be permitted without fine to be paid or without to be deposited guarantee letter from Bank, after approval of the Minister for one or more voyages, if imperative transportation or other reasons justifying sailing, or is impossible according to the circumstances the deposit of guarantee Bank letter and according to the discretion of the Minister is offered another adequate guarantee.

The fine is imposed by a reasoned decision issued by the competent authority, after a written summons of the offender, who is called to apology within 24 hours from the noticed of the decision (Note 28). The decision imposing the fine is issued not only to the responsible offender but also against to all the persons mentioned in article 12 and are considered as responsible.

Also according to article 12, paragraph 4 of PD 55/1998 in order to be ensured the costs incurred by the Public (Note 29) and by the Local Self Government Organizations (OTA) in order to prevent or to combat the pollution, is issued by the competent Authority a reasoned decision containing all the expenses against the person who caused the pollution as also and to all the responsible persons according to paragraph 1 of the same article, these are collected in accordance with the provisions of article 18 of the same law and also can be imposed the measure of vessel departure prohibition.

In the case of article 4 paragraphs 2 and 12 paragraphs (4) the Authority has discretion as the law defines "may", to impose or not the prohibition of vessel departure. But in paragraph 5 of the article 14, prohibition of vessel departure is mandatory, although is provided to the Minister of SA to allow the departure for one or more voyages, if imperative transportation or other reasons justifying sailing, or is impossible according to the circumstances the deposit of guarantee Bank letter and according to the discretion of the Minister is offered another adequate guarantee.

According to my personal opinion without having being completed the process of imposing administrative penalties by the issuing of a decision imposing a fine, at least is "legal exaggeration" to be imposed administrative measures especially since exist and the provisions of law 2690/1999, where is imposed the right of the previous hearing to the person against of who will be issued unfavorable administrative act. Finally for administratively simplicity reasons and time economy, the legislator should have left in the discretion of the Port Police Authority to impose or not the prohibition of vessel departure and not to provide this right to the maximum level of the Ministry, to the Minister.

In any case and since the time that for the certification and revenue of the fine are followed the procedures of Code of Public Income Collection (COPIC-KEDE) I think that should not impose this measure in the case of which this is left to the discretion of the Port Police Authority or to the Minister, but only in cases that the prohibition of vessels departure is related to reasons for violation of main provisions concerning pollution or contamination of the environment (e.g. article 4 paragraph2 of PD55/1998).

3.2 For Violation of Provisions and Regulations of the International Convention "For the Prevention of Pollution from Ships 1973"Marpol 73/78

The above mentioned International Convention was ratified by the law 1269/1982 (A'89). According to article 5 of this law, its provisions as also the provisions of the regulatory acts which are going to be issued according to its authorization are going to be implemented on Hellenic ships, on vessels under foreign flag arriving at Hellenic ports or in Hellenic territorial waters, at installations located in Hellas and in which are approaching ships in order to perform any kind of works and operations and finally in ships, machines, devices and any kind of equipment which is produced in Hellas and is intended for installations or vessels.

As competent authorities for its implementation (article 6) are defined the Directorate of Vessels Inspection (KEEP) (Note 30) the Port Police Authorities in Hellas and the Consular Port Police Authorities. 
In the article 8 titled "Approach prohibition and departure" is defined that "From the date on which will be in force the "Convention" is prohibited the approach to the Hellenic ports or the departure from them by Hellenic or foreign flag ships of States that does or not participate in the "Convention" if these do not conform to this".

In this case, as Convention is meant the International Convention for the prevention of pollution from ships which was signed in London in 1973 along with the attachments to this annexes I to V, Appendices and Protocols as also and the Protocol which was signed in London in 1978 and is referred to the International Convention with the attached to it annexes and appendices. Additionally is meant and the Protocol of 1997 according to is added to MARPOL annex VI, which was ratified by the law 3104/2003, where with the article 3 is extended the implementation of the provisions of law 1289/1982 and in the Protocol of 1997.

The prohibition of vessels departure in that case is mandatory and includes the Hellenic but also and the ships under foreign flag, independently if the States of their flag have acceded to the Convention or not. The compliance of the Convention terms can be ascertained by inspections, by control of shipping documents and especially from oil books, from any emergency incidents that have been occurred and have been caused maritime accident casualty or pollution etc. It is understandable that until restoration of the ship with the MARPOL conditions and until to be ascertained officially the restoration is not permitted the sailing of the ship.

In the second case and specifically in article 9 of law 1269/1982 in paragraph 3 is predicted that for infringements carried out by ships, with the notification of the decision imposing a fine can be imposed the measure of vessel departure prohibition until to be paid the fine or to be deposited a guarantee letter of equal amount. From the wording of the provision reveals that is left to the discretion of the Authority whether to impose the prohibition of vessel departure or not. According to my personal view from the time that for the certification and revenue of the fine are followed the procedures of Code of Public Income Collection (COPIC-KEDE) I think that should not be imposed this measure except in the case that is ascertained a material violation of provisions requiring rehabilitation, so that in the future the ship to ensure the environment protection.

\subsection{For Violation of Provisions and Regulations of Other International Conventions (Note 31) and International Protocols on the Protection of the Maritime Environment}

Additionally of the above national and international legal texts, which are referred to the protection of the maritime environment from pollution and is predicted and the prohibition of vessels departure case by case, are existing also the following legal texts which have been ratified by Hellas, have been incorporated into national legal order and also predict the imposition of the administrative measure of vessel departure prohibition. These are:

a. Law 314/1976 (A'106), "Ratification of the International Convention on Civil Liability for Oil Pollution Damage1969 signed in Brussels and regulating of related issues", as has been amended and being in force by the law 1638/1986 (A'108).

Penalties are predicted in article 5 as was modified by the 2881/2001 (A'16) and the prohibition of vessel departure is lifted by the deposit of guarantee letter of a Bank, functioning legally in Hellas and in an equal amount of the fine.

More specifically in the paragraph 2 of this article is predicted that the Port Police Authority may prohibit the vessel departure in case that the ship tries to sail from a Hellenic port if has violated the content of specific articles. In paragraph 3 of the same article is defined that for fines revenue are followed the procedures of Code of Public Income Collection (COPIC-KEDE)and is prohibited the vessel departure until the fine to be paid or to be deposited at the Port Police Authority which issued the fine, guarantee letter of equal amount issued by a recognized Bank.

From the wording of the provision reveals that is left to the discretion of the Authority whether to impose the prohibition of vessel departure or not. According to my personal view from the time that for the certification and revenue of the fine are followed the procedures of Code of Public Income Collection (COPIC-KEDE) I think that should not be imposed this measure except in the case that is ascertained a material violation of provisions requiring rehabilitation, so that in the future the ship to ensure the environment protection.

b. Law 855/1978 (A'235),[Ratification of the International Convention Protection of the Mediterranean Sea against Pollution with the attachment to this annex as also and the protocols «Protocol for the Prevention of Pollution of the Mediterranean Sea by Dumping from Ships and aircrafts» and "Concerning Co- operation in Combating Pollution of the oil and Other Harmful Substances in Cases of Emergency", after attachments in these Annexes signed in Barcelona in 1976] as was amended by the law 3022/2002 (A'144) paragraph(A) 3 of 
the second article and article third of law 3497/2006 (A'219).

According to article 6 paragraph 4 of this law, from the time of drafting the infringement and until the payment of the decision imposing fine which will be issued is prohibited the vessel departure.

The prohibition of vessel departure is lifted by the deposit of guarantee letter of a Bank which functions legally in Hellas and for equal amount of the fine. Sailing can be permitted without fine to be paid or without to be deposited guarantee letter from Bank, after approval of the Minister for one or more voyages, if imperative transportation or other reasons justifying sailing, or is impossible according to the circumstances the deposit of guarantee Bank letter and according to the discretion of the Minister is offered another adequate guarantee.

In this case the prohibition of vessel departure is mandatory for the Port Police Authority.

According to my personal opinion without having completed the process of imposing administrative penalties by the issuing of a decision imposing a fine, at least is "legal exaggeration" to be imposed administrative measures especially since exist and the provisions of law 2690/1999, where is imposed the right of the previous hearing to the person against of who will be issued unfavorable administrative act. Finally for administratively simplicity reasons and time economy, the legislator should have left in the discretion of the Port Police Authority to impose or not the prohibition of vessel departure and not to provide this right to the maximum level of the Ministry, to the Minister.

In any case and since the time that for the certification and revenue of the fine are followed the procedures of Code of Public Income Collection (COPIC-KEDE) I think that should not impose this measure in the case of which this is left to the discretion of the Port Police Authority or to the Minister, but only in cases that the prohibition of vessels departure is related to reasons for violation of main provisions concerning pollution or contamination of the environment.

c. Law 1147/1981 (A' 110),"Ratification of the International Convention of Dumping and Wastes and Other Matter 1973 signed in London, Mexico City, Moscow and Washington" as has been amended and being in force.

According to article 6 paragraph 4 of this law, from the time of drafting the infringement and until the payment of the decision imposing fine which will be issued is prohibited the vessel departure.

The prohibition of vessel departure is lifted by the deposit of guarantee letter of a Bank which functions legally in Hellas and for equal amount of the fine. Sailing can be permitted without fine to be paid or without to be deposited guarantee letter from Bank, after approval of the Minister for one or more voyages, if imperative transportation or other reasons justifying sailing, or is impossible according to the circumstances the deposit of guarantee Bank letter and according to the discretion of the Minister is offered another adequate guarantee.

In this case the prohibition of vessel departure is mandatory for the Port Police Authority.

According to my personal opinion without having completed the process of imposing administrative penalties by the issuing of a decision imposing a fine, at least is "legal exaggeration" to be imposed administrative measures especially since exist and the provisions of law 2690/1999, where is imposed the right of the previous hearing to the person against of who will be issued unfavorable administrative act. Finally for administratively simplicity reasons and time economy, the legislature should leave in the discretion of the Port Police Authority to impose or not the prohibition of vessel departure and not to provide this right to the maximum level of the Ministry, to the Minister.

In any case and since the time that for the certification and revenue of the fine are followed the procedures of Code of Public Income Collection (COPIC-KEDE) I think that should not impose this measure in the case of which this is left to the discretion of the Port Police Authority or to the Minister, but only in cases that the prohibition of vessels departure is related to reasons for violation of main provisions concerning pollution or contamination of the environment.

Finally is not defined what is meant by the term "other adequate insurance" leaving it in the absolute discretion of the Minister to integrate various situations according to its discretion into this category.

d. Law 1634/1986 (A'104),Ratification of the protocols 1980 «For the protection of the Mediterranean Sea against pollution from land-based sources» and 1982 «Protocol Concerning Mediterranean Special Protected Areas».

According to article 6 paragraph of the law 1147/1981 in which refers the third article of law 1634/1986, from the time of drafting the infringement and until the payment of the decision imposing fine which will be issued is prohibited the vessel departure. 
The prohibition of vessel departure is lifted by the deposit of guarantee letter of a Bank which functions legally in Hellas and for equal amount of the fine. Sailing can be permitted without fine to be paid or without to be deposited guarantee letter from Bank, after approval of the Minister for one or more voyages, if imperative transportation or other reasons justifying sailing, or is impossible according to the circumstances the deposit of guarantee Bank letter and according to the discretion of the Minister is offered another adequate guarantee.

In this case the prohibition of vessel departure is mandatory for the Port Police Authority.

According to my personal opinion without having completed the process of imposing administrative penalties by the issuing of a decision imposing a fine, at least is "legal exaggeration" to be imposed administrative measures especially since exist and the provisions of law 2690/1999, where is imposed the right of the previous hearing to the person against of who will be issued unfavorable administrative act. Finally for administratively simplicity reasons and time economy, the legislator should have left in the discretion of the Port Police Authority to impose or not the prohibition of vessel departure and not to provide this right to the maximum level of the Ministry, to the Minister.

In any case and since the time that for the certification and revenue of the fine are followed the procedures of Code of Public Income Collection (COPIC-KEDE) I think that should not impose this measure in the case of which this is left to the discretion of the Port Police Authority or to the Minister, but only in cases that the prohibition of vessels departure is related to reasons for violation of main provisions concerning pollution or contamination of the environment.

Finally is not defined what is meant by the term "other adequate insurance" leaving in the absolute discretion of the Minister to integrate various situations according to its discretion into this category.

e. Law 2252/1994 (A'192), Ratification of the International Convention "On Oil Pollution Preparedness, response and cooperation 1990 and other provisions" (Note 32).

In article 9, paragraph 1, verse 2 is defined that in the case of infringements by ships is possible with the notification of the decision imposing a fine to prohibited the vessels departure until the fine to be paid or o be deposited a guarantee letter of equal amount.

The prohibition of vessel departure is left to the discretion of the Port Police Authority and since the time that for the certification and revenue of the fine are followed the procedures of Code of Public Income Collection (COPIC-KEDE) I think that should not impose this measure in the case of which this is left to the discretion of the Port Police Authority or to the Minister, but only in cases that the prohibition of vessels departure is related to reasons for violation of main provisions concerning pollution or contamination of the environment

f. Law 3100/2003 (A'20), "Ratification of the Protocol on preparedness, response and cooperation to pollution incidents by hazardous and noxious substances, 2000".

Specifically in article 5 of that law, entitled "Implementation extension of law 2252/1994 provisions", is defined that the articles third, fourth, fifth, sixth, seventh, eighth and ninth of law 2252/1994 as being in force any time are implemented and for the "Protocol on preparedness, response and cooperation to pollution incidents by hazardous and noxious substances, 2000".

Especially in paragraph 1 (b) of article 9 of the law 2252/1994 is defined: «In the case of infringements by ships, is possible with the notification of the decision imposing a fine to be prohibited the vessel departure until the fine to be paid or be deposited a guarantee Bank letter of equal amount».

The prohibition of vessel departure is left to the discretion of the Port Police Authority and since the time that for the certification and revenue of the fine are followed the procedures of Code of Public Income Collection (COPIC-KEDE) I think that should not impose this measure in the case of which this is left to the discretion of the Port Police Authority or to the Minister, but only in cases that the prohibition of vessels departure is related to reasons for violation of main provisions concerning pollution or contamination of the environment

g. Law 3393/2005 (A'243), "Ratification of the International Convention on Civil Liability for Bunker Oil Pollution Damage, 2001".

In article 8, entitled "Penalties - Appeals" and concretely in paragraph (b) is defined that: In the case of infringements by ships, is possible with the notification of the decision imposing a fine to be prohibited the vessel departure until the fine to be paid or be deposited a guarantee Bank letter of equal amount.

The prohibition of vessel departure is left to the discretion of the Port Police Authority and since the time that for the certification and revenue of the fine are followed the procedures of Code of Public Income Collection (COPIC-KEDE) I think that should not impose this measure in the case of which this is left to the discretion of 
the Port Police Authority or to the Minister, but only in cases that the prohibition of vessels departure is related to reasons for violation of main provisions concerning pollution or contamination of the environment

h. Law 3394/2005 (A'243), "Ratification of the International Convention on the Control of Harmful AntiFowling Systems on Ships, 2001".

In article 6entitled"Penalties - Appeals", paragraph 1, verse (b) is defined: In the case of infringements by ships, is possible with the notification of the decision imposing a fine to be prohibited the vessel departure until the fine to be paid or be deposited a guarantee Bank letter of equal amount.

The prohibition of vessel departure is left to the discretion of the Port Police Authority and since the time that for the certification and revenue of the fine are followed the procedures of Code of Public Income Collection (COPIC-KEDE) I think that should not impose this measure in the case of which this is left to the discretion of the Port Police Authority or to the Minister, but only in cases that the prohibition of vessels departure is related to reasons for violation of main provisions concerning pollution or contamination of the environment

\subsection{International Convention on the Law of the Sea law 2321/1995 (A'136).}

In article 217 of the above mentioned International Convention which has been incorporated in the Hellenic legal order is defined:

(1) States shall ensure compliance by vessels flying their flag or of their registry with applicable international rules and standards, established through the competent international organization or general diplomatic conference, and with their laws and regulations adopted in accordance with this Convention for the prevention, reduction and control of pollution of the marine environment from vessels and shall accordingly adopt laws and regulations and take other measures necessary for their implementation. Flag States shall provide for the effective enforcement of such rules, standards, laws and regulations, irrespective of where a violation occurs.

(2) States shall, in particular, take appropriate measures in order to ensure that vessels flying their flag or of their registry are prohibited from sailing, until they can proceed to sea in compliance with the requirements of the international rules and standards referred to in paragraph 1, including requirements in respect of design, construction, equipment and manning of vessels.

In this case, the prohibition of vessels departure for ships which do not keep the international and national rules and regulations relating with environmental protection is mandatory and is permitted the sailing of the ship, when is ascertained competently the correction of deficiencies that had imposed the prohibition of vessels departure.

\subsection{For violations of General Ports Regulations}

They are in force the defined in article 157 paragraph 3 of LD 187/1973 (A'261).

Appeals- Suspension of decisions implementation (Note 33)

\section{Conclusions}

International, European and National legal framework which referred to items of maritime pollution is width and covers all the areas related to this. Also complete is the framework referred to legal remedies submission in the case that has been imposed administrative sanctions including the prohibition of vessels departure, a very important administrative measure.

Prohibition of vessel departure is a measure that acts either preventively or repressively. In the first case is intended to prevent the master and crew of the ship to commit an environmental pollution. In the second case the measure is imposed aiming in collecting the fine. It obvious that in the first case is prevented the pollution when is seeking to be taken concrete measures, while in the second case when the administrative measure is imposed as a mean of requirement ensuring creates problems in the operation of the ship as an economic unit.

The recognition by the legislature that the prohibition of vessel departure creates problems in its smooth functioning is confirmed so by the deposit of a guarantee letter of equal amount of the debtor in order to be the ship enable to continue the voyage, as well as with the possibility offered to the Minister to allow for specific or other reasons the continuation of the ship sailing. It must be mentioned that the Minister has not conveyed the competence to lower existing levels in order to make more flexible the enforcement of administration by Services or Port Police Authorities during its duties implementation.

Prohibition of vessel departure as an administrative measure can be imposed or as a consequential administrative penalty continuously with the imposing administrative penalty payment or alone. In the first case according to the provision that predicts the imposition of administrative penalties will be submitted the predicted case be case 
appeal and accordingly will decide on the specific measure the competent administrative or judicial bodies (Regular Administrative Justice) in accordance with the provisions of law 2690/1999 and law 2765/1999 as have been modified and being in force.

In case that has been imposed only the administrative measure concerning the prohibition of vessel departure and in that case must be followed the procedure provided by the provisions of law 2690/1999 and law 2719/1999 as have been modified and being in force and with the submission of the relevant appeals. The provisions of the aforementioned laws cover the issue of vessels departure prohibition as consequential administrative penalty or as self-administrative penalty because as was mentioned before the prohibition of vessel departure is an administrative action. But in any case is demanding special attention for the imposition of this measure in order the HCG personnel not to be engaged in penal, disciplinary and civil proceedings.

I believe that minus the cases in which exists serious reason/s in order to be imposed the prohibition of vessels departure and concretely for infringement of provisions that are related with the vessel safety, load and passengers for which/whom the imposition of the administrative meter will force/the person/s in charge to proceed in the re-establishment of lacks or in the reintroduction in the legality real situation which should be realized before the lifting of the meter from the responsible Central Service or Port Police Authority of HCG, is not needed in the rest cases to be imposed the particular meter.

This statement springs from the fact that from the moment where the income of fines are realized according to the provisions of COPIC the interests of private individuals, institutions or even of State are ensured and do not exist case of loss. This is not in effect in juridical decisions implementation. This measure should be imposed only in case of provisions infringement concerning the protection of the maritime environment, for example, does not bear the prescribed certificates, has not surrendered its remnants to host facilities, etc.

\section{References}

Asonitis, G. (1995). The United Nations Convention on the law of the sea. Papazisis, Athens (in Hellenic).

Grigoriou, P. (1996). The harmonization of Community policy on protection of the marine environment with the mutation of the community legal order. Collective volume of the Hellenic Centre for European studies, the Aegean Sea and the new Law of the Sea. Athens - Komotini, A. Sakkoulas (in Hellenic).

Hellenic Constitution. (2005). Hellenic Parliament 2005 (in Hellenic).

Korontzis, T. (2006). The enforcement of administrative police by the Hellenic Coast Guard. The institution process of the procedure for sanctions enforcement concerning the violation of Ports General Regulations. Statistic elaboration of Piraeus Port Police Authority facilitation in the period 1993-2001. Nautiki Epitheorisi, 557, 87-118 (in Hellenic).

Korontzis, T. (2007). The meaning of environment risk. Dioikitiki Enimerosi (quarterly survey of administrative science), 44, 85-97 (in Hellenic).

Korontzis, T. (2008). The vulner ability of social group sunder environmental status pressure. Dioikitiki Enimerosi (quarterly survey of administrative science), 45, 64-70 (in Hellenic).

Korontzis, T. (2009). Protection of maritime environment. The role of the Hellenic Coast Guard. Dioikitiki Enimerosi (quarterly survey of administrative science), 51, 77-90 (in Hellenic).

Korontzis, T. (2011). PhD dissertation titled The stationary role of Hellenic Coast Guard, [Public Administration Department, Law Sector], library of Panteion University of Social and Political Sciences. Athens (in Hellenic).

Korontzis, T. (2012a). The prohibition of vessels departure for reasons concerning the ensuring of public and private interests in the Hellenic legal order. International Journal of Humanities and Social Science, 2(11), 183-191.

Korontzis, T. (2012b). The prohibition of vessels departure for safety navigation reasons in the Hellenic legal order. International Journal of Asian Social Science, 2(5), 704-719.

Korontzis, T. (2012c). The Hellenic Ministry of Mercantile Marine, as an Autonomous Administrative Governmental Institution in the Period 1971-2011. A Descriptive and Critical Approach. International Journal of Business and Social Science, 3(8), 61-75.

Korontzis, T. (2012d). Penal, disciplinary and civil responsibility of the Hellenic Coast Guard personnel. International Journal of Humanities and Social Science, 2(9), 174-185.

Tsaltas, G. (2003). The international regime of the seas and oceans, international policy, international law, 
international organization, volume second. Athens, I. Sideris (in Hellenic).

\section{Notes}

Note 1. See article 1 of law 743/1977 as was codified and being in force with PD55/1998 and article 2of law 1650/1986. Also see Tsaltas, G. (2003).The international regime of the seas and oceans, international policy, international law, international organization, volume second. Athens, I. Sideris pp. 105 and next (in Hellenic).

Note 2. See Hellenic Constitution. Hellenic Parliament, January 2005, pp. 37-39.

Note 3. See article 1, paragraph (d) of law 743/1977 «Authority: Central Port Police Authorities, Port Police Authorities, Sub Port Police Authorities of the country». Additionally for the changes that have been occurred to this institution (HCG) and are related with its mission, role, constitution and subordination seePD 94/2012 (A' 149), law 3922/2011 (A'35), PD 67/2011 (A'149), PD 127/2010 (A'214), PD 184/2009 (A'21),PD 242/1999 (A'201) as has been modified and being in force.

Note 4. See Korontzis, T. (2007).The meaning of environment risk. DioikitikiEnimerosi (quarterly survey of administrative science), issue 44, pp. 85-97 (in Hellenic) and Korontzis, T. (2008). The vulner ability of social groups under environmental status pressure. Dioikitiki Enimerosi (quarterly survey of administrative science), issue 45, p.p. $64-70$ (in Hellenic).

Note 5. For the competences of this Division see article 25 of PD 67/2011 (A'149) in conjunction with article 45 of the same PD which is referred to the competences of the Port Police Authorities in Hellas. Concerning the competences of the Consular Port Police Authorities relative are the provisions of MD with Nos 1141.1/39/2002 (B'929) and 1141.1/11/2005 (B'729) and the opinion with No 49/1992 issued by the Council of the State. Also see Korontzis, T, (2012c). The Hellenic Ministry of Mercantile Marine, As an Autonomous Administrative Governmental Institution in the Period 1971-2011. A Descriptive and Critical Approach. International Journal of Business and Social Science, vol. 3, No. 8, p.p. 61-75.

Note 6. See PD 11/2002 (A' 6) titled «National emergency plan for combating pollution incidents by oil and other harmful substances» with which is established the national plan of emergency situation for combating pollution incidents by oil and other harmful substances and is reported as "national plan", as well as the MD with No 2411.1/07/03 issued by the Minister of MSA (B'850) titled: «Instructions/procedures for combating incidents of ships that are in distress or danger situation according to the requirements of article 20 of Directive 2002/59 Definition of shelter areas». See Korontzis, T (2009).Protection of maritime environment. The role of the Hellenic Coast Guard. Dioikitiki Enimerosi (quarterly survey of administrative science), issue 51, pp. 77-90 (in Hellenic).

Note 7. For a concise analysis concerning the imposed sanctions and a critical approach between the provisions of the two acts see Korontzis, T. (2009), ibid.

Note 8. See Korontzis, T. (2011). PhD dissertation titled «The stationary role of Hellenic Coast Guard», [Public Administration Department, Law Sector], library of Panteion University of Social and Political Sciences. Athens, pp. 112-119 (in Hellenic).

Note 9. A lot of MD and Joint Ministerial Decisions (JMD) have been issued according to the authorization of this law for which are imposed the administrative penalties of article 13. These are: No. 181051/2079/78 (B'1135), 181051/2078/78 (B'1135), 18051/2080/78 (B'1135), 181051/536/1980 (B'364), 1985/18051/80 (B'1110), 18051/1090/82 (B'266) 3221.2/2/89 (B'435), 3231.8/1/89 (B' 573), 3245/4/92 (B'594), 1218.91/97/97 (B'951), 3221.2/4/99 (B' 1372), 5219/F11/4/23-03-2000 (B'455), 3418/07/02 (B' 712). Finally for the MD with Nos19396/1546/97 (B'604), 69728/824/96 (B'358), 01.98012/2001/96 (B'40) are not enforced the administrative penalties of the law 743/1977, while these MD have not been issued after its authorization. Specifically have been issued after authorization of law 1650/1986 which in its provisions predicts the imposition of penal and administrative sanctions.

Note 10. Special Fund of Regulatory and City Planning Implementation (ETERPS).They are keeping in the special account «Blue Fund» as is predicted in article 18, paragraph 1 of law743/1977. It includes all the offences that are predicted in the legislation on the protection of the marine environment as also and the fines that are imposed for infringements of the provisions of law 2571/2001 (on the beach and ashore as has been modified and is in force) and is followed according to paragraph 23 of article 3 of law 2356/1994 the procedure that is mentioned in article 157 of LD 187/1973 (A'261).

Note 11. After the publication of PD 127/2010 in conjunction with the provisions of PD 67/2011 is meant the 
Division of Vessels nspection [(article 30) of PD 67/2011].

Note 12. Has been issued the PD 400/1996 (A'268).

Note 13. Has been issued the MD 1218/2/97 (B' 534).

Note 14. See paragraph 2 of the one article of PD 86/1997 (A'72).

Note 15. See law 356/1974 (A'90).

Note 16. See op. cit. note 10.

Note 17. Concerning the United Nations Convention on the Law of The sea (UNCLOS) which was ratified by the Hellas with the law 2321/1995 is recognized the right for intervention on the high seas only to the State of which the vessel bears the flag. According to article 221 of the above mentioned Convention is introduced variation, stating that Member States can adopt and implement measures in accordance with the customary and conventional international law, beyond the territorial waters, depending on the actual or threatened damage in order to protect the coasts, or their related interests including fishing, from pollution or threat of pollution, due to a maritime accident or from actions that have relation with this accident which may have as result the causing of serious damage.

Note 18. See JMD with No 747/Ф 183507/87 (B'226).

Note 19. After authorization of this law has been issued the JMD with No1218.91/97 issued on October 15, 1997 (B'951) and MD with No3221.2/1/99 (B'76) issued by the Minister of Mercantile Marine for which are implemented the penalties of article 9 of the same law.

Note 20. See note 11 .

Note 21. In article 4 of the law 3528/2007 (A'122) was defined the "Establishment - Mission of HCG Operations Center". Specifically in the HCG Headquarter established Operation Center which its mission is the management, monitoring and coordinating of large-scale operations with the use of the infrastructure, the available means and HCG personnel, the monitoring of small-scale operations carried out by the local Port Police Authorities, as well as the provider of the necessary assistance to them except facts or search and rescue operations. Relative is the "Regulation of organization and function of HCG (KEPIX/HCG)", with No 09/09 which was ratified by the MD with No7100/02/09 issued on May 21, 2009by the Minister of Mercantile Marine, which was issued on implementation of article 4 of the law 3528/2007 (A'122) and article 126 paragraph3 verse (d) and (e) of law 3079/2002 (A'311).

Note 22. See note 11.

Note 23. It is expected the incorporation in the Hellenic legislation with injunction of the Ministry the Ministry of Justice, Transparency and Human Rights. This specific directive is complemented by detailed rules on criminal offences and other provisions contained in Council framework decision with No 2005/667/JHA issued of July 12, 2005 in order to be strengthen the legislative framework for the enforcement of the law against ship-source pollution.

See Grigoriou, P. (1996). The harmonization of Community policy on protection of the marine environment with the mutation of the community legal order. in the collective volume of the Hellenic Centre for European studies, the Aegean Sea and the new Law of the Sea. Athens - Komotini, A. Sakkoulas, pp. 271-290 (in Hellenic).

Note 24. See Asonitis, G. (1995). The United Nations Convention on the law of the sea. Papazisis, Athens, pp. 98 and next (in Hellenic).

Note 25. See Korontzis, T. (2006). The enforcement of administrative police by the Hellenic Coasty Guard. The institution process of the procedure for sanctions enforcement concerning the violation of Ports General Regulations. Statistic elaboration of Piraeus Port Police Authority facilitation in the period 1993-2001.Nautiki Epitheorisi, issue 557, pp. 87-118 (in Hellenic).

Note 26. See Korontzis, T. (2011), op.cit. note 8, pp.156-157.

Note 27. For conceptual determination see Korontzis, T. (2011), note8, p.p. 171-173.

Note 28. In the provisions of law 2690/99 and more specifically in article 6 titled «previous hearing of the interested» paragraph 2 is determined that the period in which the person has the right to express to the administrative authorities his/her/it opinion/s writing or orally before each action or measure against his/her/its rights or interests is five (05) full days.

In article 157 paragraph 1 of LD 187/1973 (A'261) is determined period of 24hoursin order the interested to 
apologize.

Taking under consideration article 33 of law 2690/1999 and specifically paragraph1 in which is determined:«From the entry into force of the code, if is not otherwise specified, is deleted any general provision which refers in item regulates by it» in conjunction with the fact that a new law in force is regulated an item which was reported in LD 187/1973 ( $\mathrm{A}^{\prime} 261$ ), as also the fact that extends the right of citizen protection dual in time and in material by establishing and other measures for the protection of citizen (article 6 paragraph 3, 24, 25, 27), the provision of article 157 paragraph 1 of LD 187/1973 concerning the period for apology must be considered as abolished.

Note 29. Concerning the cost of the time use for floating, land and air craft means of HCG, the personnel remuneration that employed as also the cost of other means and materials used or were spent for combating of pollution incidents has issued in implementation of paragraph 4 of article 12 the MD with No. 3221.2/4/99 (B'1372) issued by the Minister of Mercantile Marine.

Note 30. See op. cit. note 11.

Note 31 . Seenote 17.

Note 32. See note 19.

Note 33. Korontzis, T. (2012a). The prohibition of vessels departure for reasons concerning the ensuring of public and private interests in the Hellenic legal order.International Journal of Humanities and Social Science, Vol. 2, issue 11, pp. 183-191, Korontzis, T. (2012b). The prohibition of vessels departure for safety navigation reasons in the Hellenic legal order. International Journal of Asian Social Science, Vol. 2, issue 5, pp.704-719 and Korontzis, T. (2011). PhD dissertation, op.cit.pp. 171-214 (in Hellenic). Concerning the penal, disciplinary and civil responsibility of HCG personnel see Korontzis, T. (2012d).Penal, disciplinary and civil responsibility of the Hellenic Coast Guard personnel.International Journal of Humanities and Social Science, Vol. 2, issue 9, pp.174-185 